\title{
On the Use of Laser Ablation for Cleaning High Voltage Ceramic Insulators
}

\author{
E. de Posada, L. Moreira, M. Arronte, L. Ponce, T. Flores \\ IPN CICATA ALTAMIRA, km 14.5 Carretera Tampico-Puerto Industrial Altamira, Altamira, México \\ Email: Iponce@ipn.mx
}

Received 20 June 2014; revised 18 July 2014; accepted 4 August 2014

Copyright (C) 2014 by authors and Scientific Research Publishing Inc.

This work is licensed under the Creative Commons Attribution International License (CC BY).

http://creativecommons.org/licenses/by/4.0/

(c) (i) Open Access

\begin{abstract}
High voltage lines are one of the main ways for carrying electric energy. To do so high voltage insulators are needed to insulate these lines from the supporting towers. Glass, ceramic and polymer insulators are widely used. Generally high voltage insulators are exposed to weather where humidity, from rain and moist, together with pollution allows accumulation of unwanted material on the surface of the insulator. Cleaning procedures are then needed to remove such material and avoid short-circuiting. The most commonly used cleaning methods are hand cleaning using chemicals that need turning off the main and water jet, which allows keeping the line in service. In this work we explore the possibility of using laser ablation for cleaning high voltage ceramic insulators. It is demonstrated that cleaning can be accomplished by a two-step process. First a Q-switched Nd: YAG laser is used to ablate the unwanted material. The second step is to use a free running Nd: YAG laser to restore the surface hydrophobicity of ceramic insulator, which is affected in the first process step.
\end{abstract}

\section{Keywords}

Laser Processing, Surface Cleaning, Hydrophobicity

\section{Introduction}

Both, industrial development and growth of earth population bring the need for increasing electric energy production. Transmission of electricity is always done at high voltages which decreases amount of current carried by electric conductors. However such high voltages imply the use of insulators that keep conductors lines at safe distances avoiding mortal accidents and short circuiting. Glass, ceramic and polymer insulators are widely used.

Generally high voltage insulators are exposed to weather where humidity, from rain and moist, together with pollution allows accumulation of unwanted material on the surface of the insulator. If such material is not re- 
moved the surface dielectricity is decreased and short circuit paths are created, that is why cleaning procedures are implemented. The most commonly used cleaning methods are hand cleaning using chemicals that involves high risk for working personal requiring quite often putting off service the conduction line and water jets, which do not implies the latter.

Disregarding the insulator material a key property is the hydrophobicity of its surface as water droplets are most of the time responsible for nucleating unwanted material, which could be pollution or even icing in cold weathers [1].

Laser ablation is well known method for cleaning and it has been used in art restoration and graffiti removal [2], metal cleaning [3], food products cleaning [4], among others. However to the extent of the literature search done for the completion of this work, there is no report of using it for cleaning high voltage insulators. The aim of the present work is to explore the possibility of using laser ablation as an alternative cleaning method. If such method is reliable two main advantages can be foreseeing, no risk to working personal as there is not possibility for current conduction and reduction of waste associated to water jet method.

\section{Experimental Detail}

A ceramic high voltage insulator, supplied by the Mexican Federal Commission for Electricity (CFE in Spanish), was cut in pieces as to select different working zones. A homemade Nd: YAG (1064 nm) laser capable of working both regimes, free running and Q-switched, was used to clean the insulator surface. Laser pulse durations at full width half maximum were $100 \mu$ s and 50 ns for free running and Q-switched regimes, respectively. Pulse energy was varied using a beam attenuator.

The criteria to evaluate the cleaning process were a bare eye inspection to corroborate that unwanted material was fully removed and the hydrophobicity property of the treated zone.

The angle of contact of a water droplet on the treated zone, following the STRI method, was used to know the effect of laser ablation on the hydrophobic property [5]. An insulin syringe was used to place constant volume deionised water droplets, then using a Digital Blue QX5 optical microscope with a 10x objective images of the droplets were acquired. The contact angle was measured after processing the images and averaging over ten droplets per each treated zone. Figure 1 shows a scheme of the used set up.

Before start the laser ablation experiment it was determined that damage threshold of the insulator surface was over $50 \mathrm{~J} \cdot \mathrm{cm}^{-2}$.

\section{Results and Discussion}

Figure 2 shows an image of a sample of the ceramic insulator after been processed using the two laser regimes. In the case of free running regime the laser pulse fluence was varied from $5 \mathrm{~J} \cdot \mathrm{cm}^{-2}$ to $31 \mathrm{~J} \cdot \mathrm{cm}^{-2}$. However, the yellowish color of treated zones, reveal that it was not possible to obtain a clean surface. See top part of Figure 2. To some extent it is an expectable result if we take into account the strong thermal component that characterizes the interaction of long infrared laser pulses with materials. On the other hand a complete material removal was achieved when using the Q-switched regime, for all used laser pulse fluencies $\left(0.5 \mathrm{~J} \cdot \mathrm{cm}^{-2}\right.$ to $\left.15 \mathrm{~J} \cdot \mathrm{cm}^{-2}\right)$, as it can be observed in the center area of Figure 2. It should be noted that depending of laser pulse fluence and amount of pollution, no more of 10 shots were needed to reach a cleaned surface. Once more a result consistent with the well-known ability of nanosecond laser pulses to ablate material [6].

As it was mentioned before, that measurements of insulator surface hydrophobicity were performed as to evaluate if it is affected by the laser ablation process. Firstly, an area unaffected by the pollution was used to know the original hydrophobic property of the insulator. Figure 3(A) shows that the average contact angle is 56.50 , which falls within the HC2 classification of the STRI. It can be observed in Figure 3(Q) that the average contact angle decreases to 38.70 after the cleaning process using Q-switch regime. This value falls within the $\mathrm{HC}_{3}$ classification of the STRI [5] which is not very good for an insulator.

Then the following experiment was carried out. Three different zones of the insulator surface, previously cleaned using the Q-switch regime, were irradiated for the same period of time $(1 \mathrm{~min})$ using different pulse fluencies in the free running regime. Figure 4 shows images of the water droplets and the average contact angles for each case. It can be observed that contact angle (hydrophobic properties of the insulator surface) were recovered and even improved respect to initial value of the untreated insulator. Figure 5 shows a plot of the droplet 


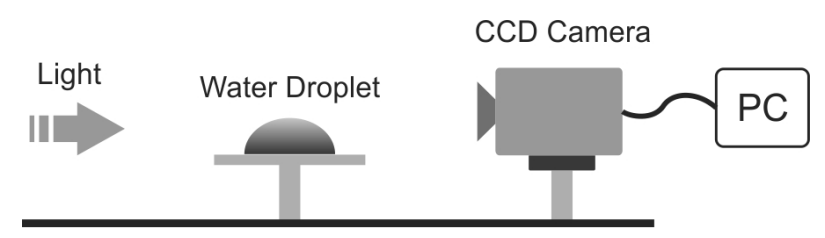

Figure 1. Water droplet contact angle measurement set up.



Figure 2. Image of a sample of the ceramic insulator after been processed using the two laser regimes. Top part shows a yellowish area after using free running regime. Center part is a clean surface as obtained using Q-switched regime.

A

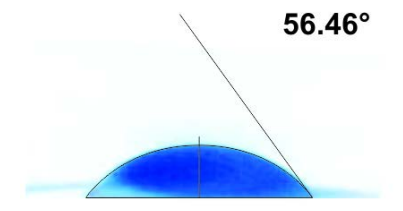

$\mathbf{Q}$

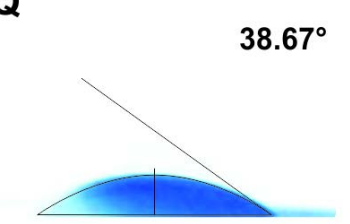

Figure 3. Images of water droplets and measured contact angle of an area unaffected by pollution (A) and a surface treated with the laser in Q-switch regime $(\mathrm{Q})$.

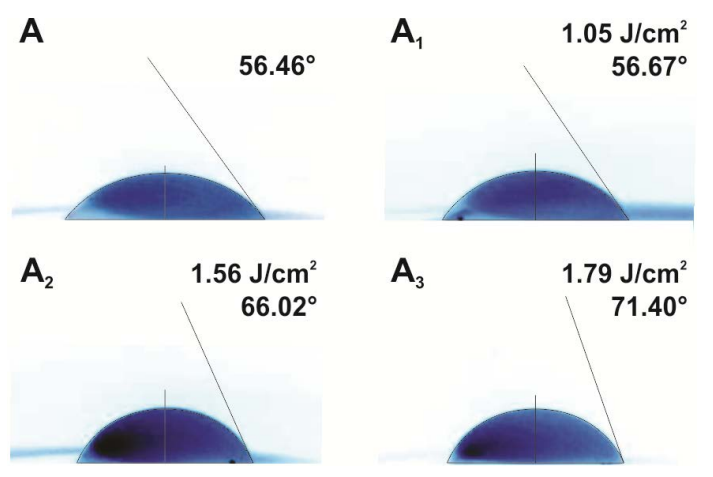

Figure 4. Images of water droplets and measured contact angle of an area unaffected by pollution (A) and surfaces treated with different free running laser fluencies $\left(A_{1}-A_{3}\right)$.

contact angle as a function of the laser pulse fluence, where it can be observed it shows a linear relation.

There can be several explanations for such result. It is well known that surface patterning can lead to superhydrophobicity, which has been obtained by modifying the surface using plasma treatment, photolithography, selective growth of carbon nanotubes as well as laser patterning [1] [7]. It can also be related to decrease of the surface energy as the long laser pulses of free running regime give enough energy and time for a redistribution of energy centers created during the high peak power short pulses of the Q-switched regime. Yet a precise explanation of such result requires further study. 


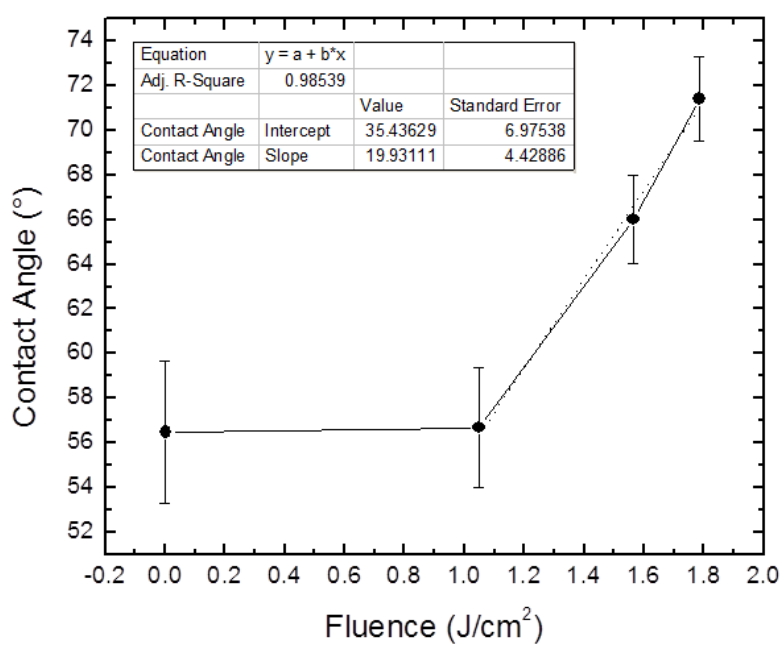

Figure 5. Plot of droplet contact angle as a function of the fluence of free running laser pulses. A linear relation is obtained.

\section{Conclusions}

It was demonstrated that Q-switched (50 ns) Nd: YAG (1064 nm) lasers can be used to clean high voltage ceramic insulators. Due to the high damage threshold of the glazed surface high pulse fluencies $\left(15 \mathrm{~J} \cdot \mathrm{cm}^{-2}\right)$ can be used as to ablate almost any pollution. Although surface hydrophobicity is deteriorated by the Q-switched laser pulses a simple treatment of the surface using free running laser pulses $\left(100 \mu \mathrm{s}, 1 \mathrm{~J} \cdot \mathrm{cm}^{-2}-2 \mathrm{~J} \cdot \mathrm{cm}^{-2}\right)$ restore and even improve the hydrophobicity. To the extent of our experiments there is linear relation between the increase of the droplet contact angle and the laser pulse fluence in the free running regime.

Further experiments are needed to identify the process by which hydrophobicity is being improved as well as to corroborate if the same results can be obtained for insulators of other materials. Yet the work presented here puts laser ablation as an alternative technique for the maintenance of high voltage insulators offering, among other advantages, no risk to working personal as there is no possibility for current conduction and reduction of waste associated to water jet method.

\section{Acknowledgements}

Authors would like to acknowledge the support of the Mexican National Council of Science and Technology (CONACyT) for their support through the projects CB \# 101239 and FONSEC CFE 2008-C07-89275.

\section{References}

[1] Yushun, Z., Jian, L., Jianlin, H. and Grzybowski, S. (2010) Icing Performances of Super-Hydrophobic PDMS/Nano-Silica Hybrid Coating on Insulators. 2010 International Conference on High Voltage Engineering and Application (ICHVE), 11-14 October 2010, 489-492.

[2] Cooper, M., Zafiropulos, V., Fotakis, C. and Larson, J. (1993) Laser Cleaning in Conservation: An Introduction. Butterworth Heineman, Oxford.

[3] Ponce, L.V., Hernandez, M.P., Flores, T., Morejon, D. and Peña, J.L. (2005) Surface Effects in Cu0.64Zn0.36 Alloy Produced by CO2 Laser Treatment. Materials Letters, 59, 3909-3912. http://dx.doi.org/10.1016/j.matlet.2005.07.031

[4] Ponce, L., Flores, T., Arronte, M., Parfenov, V.A., Koval’chuk, L.V. and Bartoli, L. (2008) Laser Processing of Cactuses of the Opuntia Family. Journal of Optical Technology, 75, 490-494. http://dx.doi.org/10.1364/JOT.75.000490

[5] Guide, S. (1992) 1, 92/1. Hydrophobicity Classification Guide.

[6] Phipps, C., Birkan, M., Bohn, W., Eckel, H.-A., Horisawa, H., Lippert, T., Michaelis, M., Rezunkov, Y., Sasoh, A. and Schall, W. (2010) Review: Laser-Ablation Propulsion. Journal of Propulsion and Power, 26, 609-637. http://dx.doi.org/10.2514/1.43733

[7] Zorba, V., Persano, L., Pisignano, D., Athanassiou, A., Stratakis, E., Cingolani, R., Tzanetakis, P. and Fotakis, C. 
E. de Posada et al.

(2006) Making Silicon Hydrophobic: Wettability Control by Two-Lengthscale Simultaneous Patterning with Femtosecond Laser Irradiation. Nanotechnology, 17, 3234. http://dx.doi.org/10.1088/0957-4484/17/13/026 
Scientific Research Publishing (SCIRP) is one of the largest Open Access journal publishers. It is currently publishing more than 200 open access, online, peer-reviewed journals covering a wide range of academic disciplines. SCIRP serves the worldwide academic communities and contributes to the progress and application of science with its publication.

Other selected journals from SCIRP are listed as below. Submit your manuscript to us via either submit@scirp.org or Online Submission Portal.
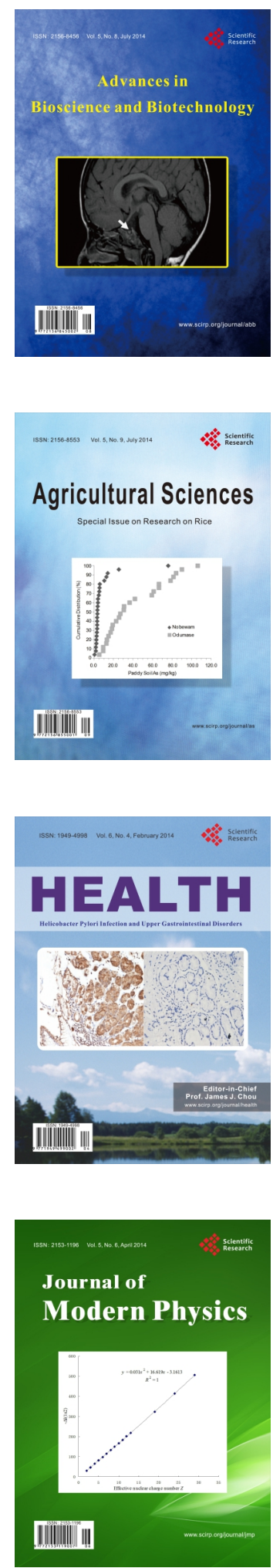
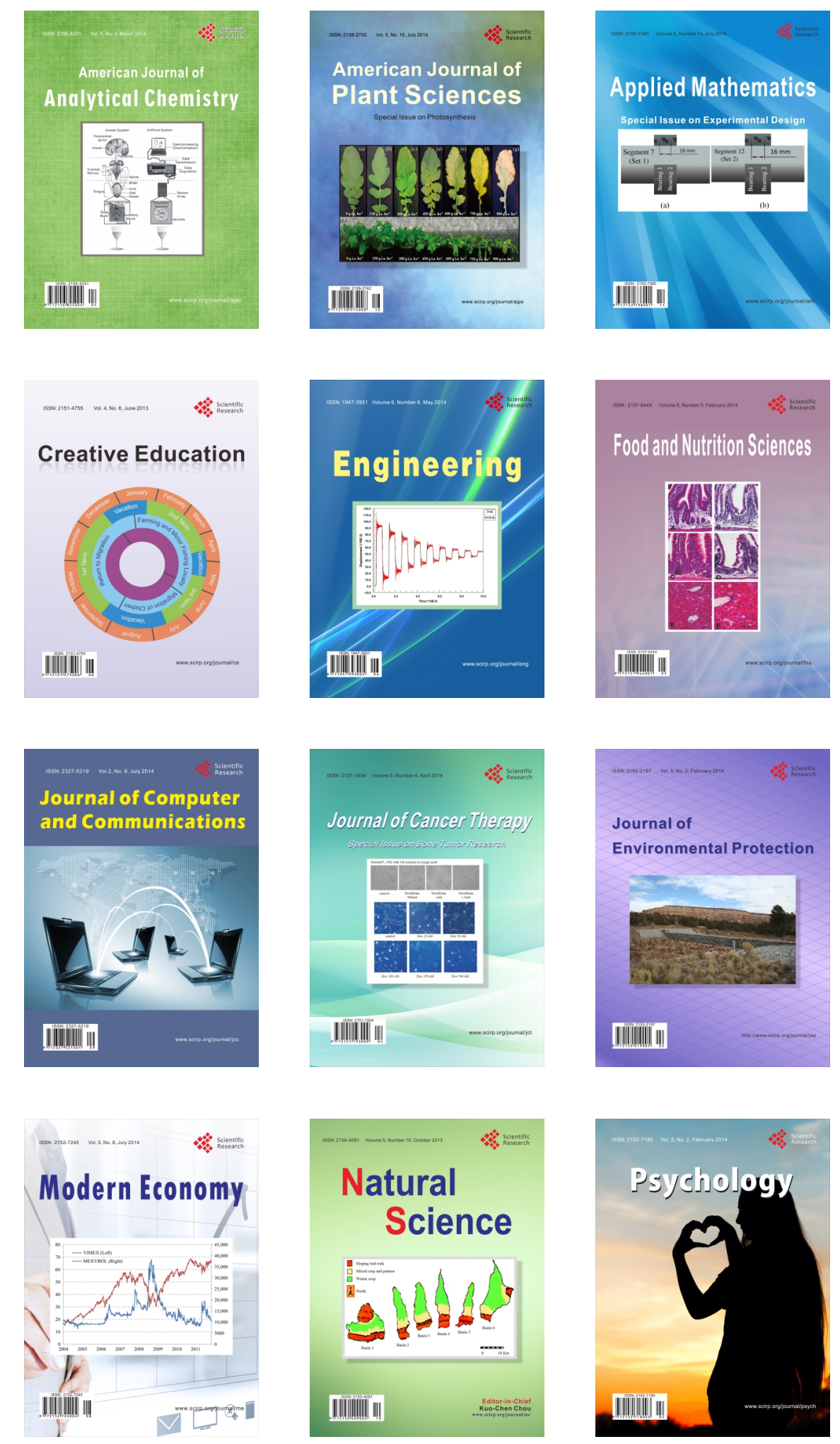